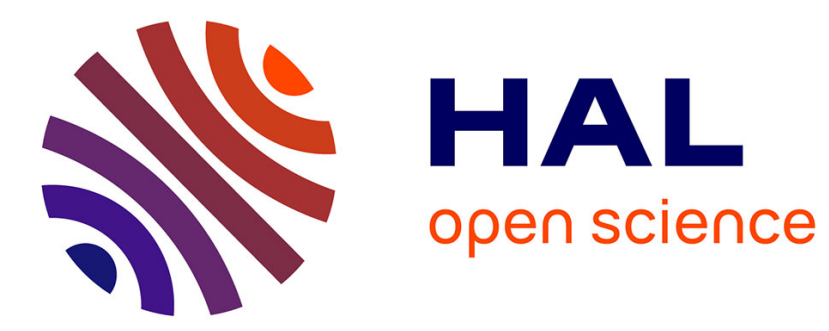

\title{
Polymer rheology at high shear rate for microinjection moulding
}

Cheima Mnekbi, Michel Vincent, Jean-François Agassant

\section{To cite this version:}

Cheima Mnekbi, Michel Vincent, Jean-François Agassant. Polymer rheology at high shear rate for microinjection moulding. 13th ESAFORM Conference on Material Forming, Apr 2010, Brescia, Italy. pp.Pages 539-542, 10.1007/s12289-010-0826-9 . hal-00572536

\section{HAL Id: hal-00572536 \\ https: / hal-mines-paristech.archives-ouvertes.fr/hal-00572536}

Submitted on 14 Aug 2013

HAL is a multi-disciplinary open access archive for the deposit and dissemination of scientific research documents, whether they are published or not. The documents may come from teaching and research institutions in France or abroad, or from public or private research centers.
L'archive ouverte pluridisciplinaire HAL, est destinée au dépôt et à la diffusion de documents scientifiques de niveau recherche, publiés ou non, émanant des établissements d'enseignement et de recherche français ou étrangers, des laboratoires publics ou privés. 


\title{
POLYMER RHEOLOGY AT HIGH SHEAR RATE FOR MICROINJECTION MOULDING
}

\author{
C. Mnekbi ${ }^{*}$, M. Vincent, J.F. Agassant \\ Mines ParisTech - Centre de Mise en Forme des Matériaux, CNRS UMR 7635 - Sophia-Antipolis, France
}

\begin{abstract}
In this paper, we present the rheology of a high-density polyethylene for microinjection moulding. At high flow rate, pressure becomes high enough so that shear heating and pressure-dependence of the viscosity cannot be neglected. Moreover, spurt and chaotic defects related to wall slip were encountered. Nevertheless, we used classical data processing. We obtained viscosity at high shear rate which is lower than the viscosity obtained with the CarreauYasuda extrapolation of the moderate shear rate data. In order to discuss the origin of this difference, we developed a flow numerical simulation in the capillary where we take into account pressure and temperature dependent viscosity. The relative importance of these phenomena and their coupling is presented.

Then, injection moulding experiments were carried out in a plaque mould. Different moulding parameters were tested. A three dimensional injection moulding numerical simulation, using Rem3D software, was carried out. The quality of the different sets of rheological data is assessed by comparing computed and measured pressure.
\end{abstract}

KEYWORDS: Microinjection moulding, high shear rate, HDPE, numerical simulation, Rem3D.

\section{INTRODUCTION}

In microinjection moulding, high velocity combined to small flow gaps lead to different flow behaviour compared to classical injection moulding [1]. One of the questions is the viscosity data at high shear rate [2,3], as numerical simulation of mould filling requires precise rheological data. The aim of this work is to identify what physics is involved in such conditions, to obtain viscous rheological data, and to test them by comparing the results of numerical simulation to measurements in an instrumented mould.

\section{HDPE RHEOLOGY}

\subsection{RHEOLOGY EXPERIMENTS}

\subsubsection{Material}

A commercial semi-crystalline thermoplastic, HDPE (high-density polyethylene) with the grade ELTEX HD 6070 , is supplied by Ineos. As the HDPE was not stabilised by the supplier, we added $0.1 \%$ of a stabilizer (IRGANOX).

\subsubsection{Experimental protocol}

A rotational rheometer (ARES) is used in dynamic oscillatory mode to determine polymer linear viscoelastic properties at imposed strain. Measurements are performed in a frequency sweep mode (0.1 to 100 $\mathrm{rad} / \mathrm{s})$, at an imposed strain of $10 \%$, for temperatures between 140 and $190{ }^{\circ} \mathrm{C}$. The viscosity, the elastic modulus G' and the viscous modulus G" are determined.
Then according to the time-temperature superposition principle, the experimental results are superposed on a master curve at a reference temperature, by means of a shift factor $\mathrm{a}_{\mathrm{T}}$.

A capillary rheometer, the Rheoplast, has a conical Couette plastication zone, in which the polymer is melted by shear-heating and by conduction, then relaxed to homogenize the temperature and finally extruded into a capillary. A pressure transducer is mounted immediately above the capillary to record the pressure drop.

The capillary rheometer is used with six dies with diameter $\mathrm{D}$ equal to $1 \mathrm{~mm}$ and $0.5 \mathrm{~mm}$, and length over diameter $\mathrm{L} / \mathrm{D}$ ratio equal to 4,8 and 16 respectively, at $190^{\circ} \mathrm{C}$, for injection volume flow rates between 2 and $1018 \mathrm{~mm}^{3} \cdot \mathrm{s}^{-1}$. The maximum recorded pressure is 60 $\mathrm{MPa}$.

\subsubsection{Flow hypothesis}

We suppose a certain number of assumptions for the evaluation of capillary data:

- flow is incompressible, isothermal and established;

- melt sticks to the wall;

- viscosity is not pressure dependent.

These assumptions permit to use Bagley and Rabinowitsch corrections.

\subsubsection{Experimental results}

First, we selected the large diameter $1 \mathrm{~mm}$. We limited apparent shear rate value to a maximum of $10^{4} \mathrm{~s}^{-1}$. We 
did not observe extrusion defects. In those conditions the assumptions set out above are true and classical Bagley and Rabinowitsch corrections can be used [4].

Time-temperature superposition was done according to a shift factor to a reference temperature of $190^{\circ} \mathrm{C}$.

The viscosity versus the frequency given by the ARES and the viscosity versus the shear rate given by the Rheoplast are shown in Figure 1. We can see that the Cox-Merz transformation is satisfied.

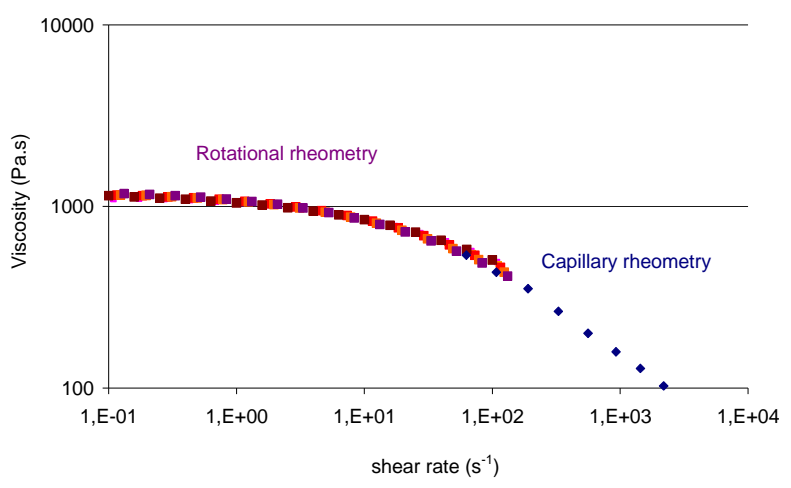

Figure 1: Rotational and capillary rheometries results superimposed for HDPE AT $190^{\circ} \mathrm{C}$

In a second step, we imposed high injection speed in the capillary rheometer using the $0.5 \mathrm{~mm}$ die diameter. We reach high shear rates values up to $10^{5} \mathrm{~s}^{-1}$.

Around a shear rate value of $10^{4} \mathrm{~s}^{-1}$, we observe polymer spurt, then chaotic defects. However, the evolution of measured pressure for a constant shear rate still gives a plateau, which permits the determination of a flow curve. HDPE measurements for high shear rate leads to high pressure values up to $60 \mathrm{MPa}$.

At such a pressure level, dissipative heating and pressure dependent viscosity are no longer negligible [5]. Dissipative heating decreases the viscosity, whereas the rise of pressure enhances the viscosity. Both of these dependencies are estimated afterwards in this paper. We also choose to neglect the extrusion defects for data processing. We employ Bagley and Rabinowitsch corrections to draw viscosity behaviour.

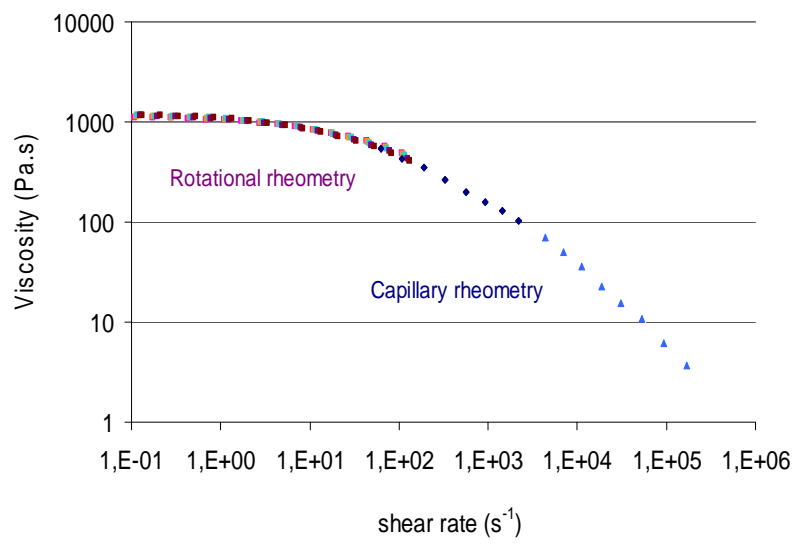

Figure 2: Rotational and high shear rate capillary rheometries results superimposed for HDPE AT $190^{\circ} \mathrm{C}$
An extended viscosity curve given by the capillary rheometry is superimposed on the results of Figure 1. The shear rate reaches $10^{5} \mathrm{~s}^{-1}$ (Figure 2). The viscosity at high shear rate is lower than the viscosity with the Carreau-Yasuda extrapolation of the moderate shear rate data.

\subsection{CAPILLARY FLOW SIMULATION WITH TEMPERATURE AND PRESSURE DEPENDENCE OF VISCOSITY}

\subsubsection{Theoretical issues}

At high shear rate, the dissipative heating and pressure dependence of viscosity have to be taken into account [6]. A capillary flow simulation take into account the dissipative and pressure dependent viscosity effect on the pressure.

The viscosity function is expressed by a Carreau-Yasuda law (equation 1).

$$
\eta(\dot{\gamma})=\eta_{0}\left[1+(\lambda \dot{\gamma})^{a}\right]^{\left(\frac{m-1}{a}\right)}
$$

$\eta_{0}$ is zero shear rate viscosity (at $\mathrm{T}_{0}$ reference temperature and $P_{0}$ atmospheric pressure), $\lambda$ is a characteristic time, $m$ is the power law exponent and $a$ transition width parameter.

The temperature shift factor follows Arrhenius law, (equation 2), as we work with a semi-crystalline thermoplastic:

$$
a_{T}=\exp \left[\frac{E a}{R}\left(\frac{1}{T}-\frac{1}{T_{0}}\right)\right]
$$

$E a$ is the activation energy.

Shear rate and temperature dependent viscosity is calculated according to equation 3 .

$$
\eta(\dot{\gamma}, T)=a_{T} \eta\left(\dot{\gamma} a_{T}, T_{0}\right)
$$

Shear rate and pressure dependent viscosity (equation 4)

$$
\eta(\dot{\gamma}, P)=\exp (\chi P) \cdot \eta(\exp (\chi P) \cdot \dot{\gamma})
$$

We can combine both the pressure and temperature dependency of viscosity (equation 5).

$$
\eta(\dot{\gamma}, T, P)=\exp (\chi P) \cdot a_{T} \eta\left(. \exp (\chi P) \cdot \dot{\gamma} \cdot a_{T}, T_{0}\right)
$$

We assume that the velocity vector is parallel to the tube axis, and the component parallel of the axis $\mathrm{z}, w$, is only a function of the radius $r$. We assume a generalized Newtonian behaviour law. Neglecting gravity and inertia, the force balance equation leads to:

$$
w(r)=\left[\int_{R}^{r} \frac{r}{2 \eta} d r\right] \frac{d p}{d z}
$$

The integration of the flow velocity leads to volume flow rate $Q$ :

$$
Q=2 \pi \int_{0}^{R} w(r) r d r=2 \pi \frac{d p}{d z} \int_{0}^{R}\left(\int_{R}^{r} \frac{r d r}{2 \eta}\right) r d r
$$


We use a slab method to define a bi-dimensional meshing of the capillary. The pressure variation in slab $n$ of length $\Delta z$ is given by:

$$
\Delta P_{n}=\Delta z \frac{Q}{2 \pi \int_{0}^{R}\left(\int_{R}^{r} \frac{r d r}{2 \eta\left(T_{n-1}, P_{n-1}, \dot{\gamma}_{n-1}\right.}\right) r d r}
$$

To determine the temperature regime in the capillary, we calculate the Cameron number for the dissipative heating characterisation. In our case, $\mathrm{Ca} \leq 10^{-2}$, the temperature regime is adiabatic.

Dissipative heating for an adiabatic temperature regime in a slab is expressed by (9).

$$
\Delta T_{n}=\frac{\Delta P_{n}}{\rho . c}
$$

Where $\rho$ is the density and $c$ is the specific heat capacity. The simulation is run with a power law initialisation in the first slab. Then, we calculate $\Delta \mathrm{P}_{i}$ and $\Delta \mathrm{T}_{i}$ in each slab $i$ successively. At the end of calculi, we deduce the $\mathrm{P}_{i}$ values.

\subsubsection{Modelling results}

We simulate the HDPE flow into a die with a ratio L/D of 8 at $200^{\circ} \mathrm{C}$. The geometry of the slab method simulation is given by Figure 3. The material parameters are listed in Table 1.

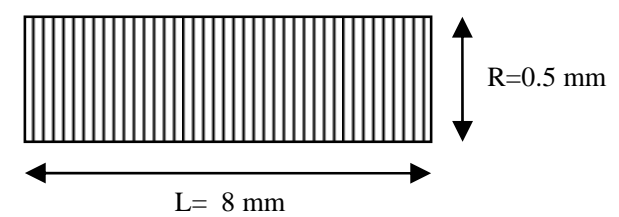

Figure 3: Slab method simulation geometry

We study four cases of flow simulation:

- $\eta(\dot{\gamma}) ; \eta(\dot{\gamma}, T) ; \eta(\dot{\gamma}, p)$ and $\eta(\dot{\gamma}, T, p)$.

Figure 4 shows the four curves of pressure profile for an imposed shear rate of $10^{5} \mathrm{~s}^{-1}$.

Table 1: HDPE parameters at $190^{\circ} \mathrm{C}$

\begin{tabular}{lll}
\hline Zero shear viscosity & $\eta_{0}[\mathrm{~Pa} . \mathrm{s}]$ & 1200 \\
\hline Zero characteristic time & $\lambda[\mathrm{s}]$ & 0.01 \\
Transition width parameter & $a$ & 1 \\
Power law exponent & $m$ & 0.27 \\
Piezodependency coefficient & $X\left[\mathrm{~Pa}^{-1}\right]$ & $2.10^{-8}$ \\
Heat capacity & $\rho . c$ & $2.10^{-6}$ \\
& {$\left[\mathrm{~J} /{ }^{\circ} \mathrm{Cm}^{3}\right]$} & \\
Activation energy & $E_{a}$ & 20 \\
& {$[\mathrm{~kJ} / \mathrm{mole}]$} &
\end{tabular}

Different moulding parameters were tested.

Figure 6 shows the pressures and temperatures recorded during an injection moulding test, with a pneumatic injection pressure of $0.5 \mathrm{MPa}$. The melt temperature is 
$240^{\circ} \mathrm{C}$ and the mould temperature is $75^{\circ} \mathrm{C}$. The average shear rate reached $5.10^{4} \mathrm{~s}^{-1}$. We can see that the displacement of the screw vs. time is not linear. Therefore, the entrance flow rate is not constant.

At the end of mould filling, at $0.29 \mathrm{~s}$, we observe a pressure increase due to the material compressibility.

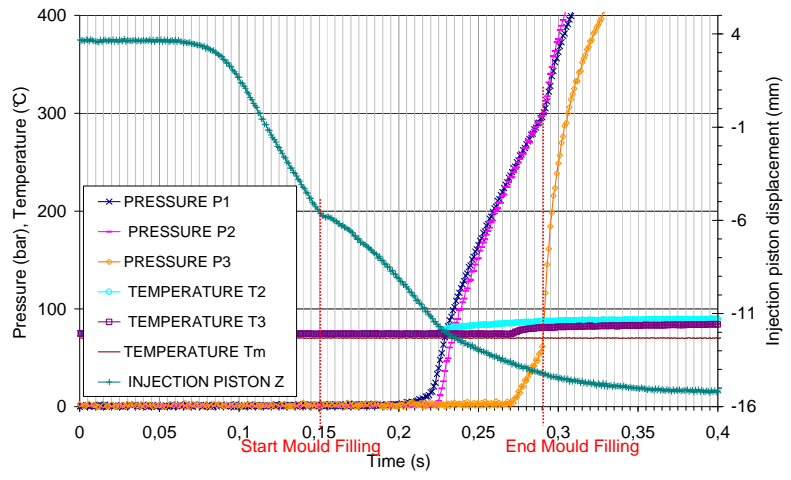

Figure 6: HDPE injection moulding test acquisition

\subsection{INJECTION MOULDING SIMULATION}

A three dimensional injection moulding numerical simulation, using Rem3D software, was carried out. This simulation was based on finite element equation solvers (a flow Stokes solver, a flow front transport equation solver and a heat equation solver). The entire cavity to be filled was meshed with tetrahedral elements using a fully automatic 3D mesh generator. The finite element method was used to solve the thermo-mechanical equilibrium equations at each time step of the process.

We used a thermo dependent Carreau-Yassuda law taking into account the material compressibility.

The filled part is shown in Figure 6. The quality of the different sets of rheological data is assessed by comparing computed and measured pressure Figure 7.

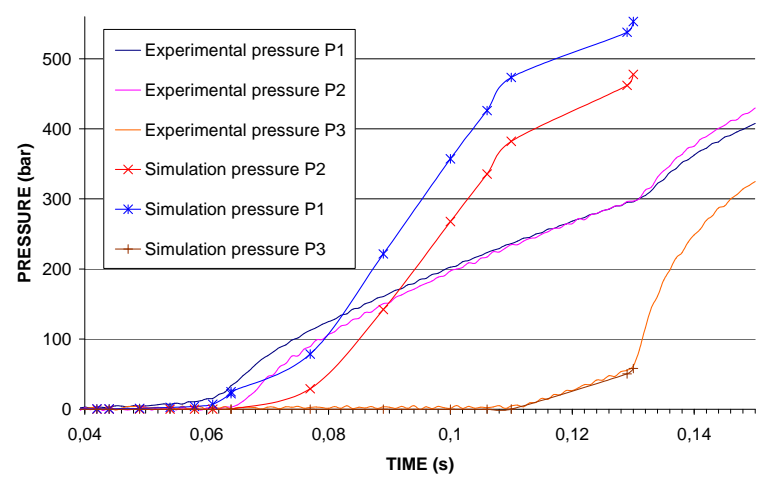

Figure 7: Measured and computed pressures comparisons

The starts of each pressure P1, P2 and P3 are well reproduced by the computation. The filling end coincides in both cases. Nevertheless, the computed pressure values $\mathrm{P} 1$ and $\mathrm{P} 2$ are more important than the experimental ones. This can be due to the incertitude of the introduced flow rates in the simulation. Another hypothesis for this difference is the material data. We consider a rheolgy neglecting the wall sleep related to the extrusion defects and observed in the flow curves. A wall sleep causes a pressure decrease in the measured case.

\section{CONCLUSIONS}

We presented the rheology of a high-density polyethylene. When we used a capillary rheometer with conventional diameter $(1 \mathrm{~mm})$ and injection speed, we obtained viscosity data up to an apparent shear rate of $10^{3} \mathrm{~s}^{-1}$. When using smaller diameter $(0.5 \mathrm{~mm})$ at high injection rate, the apparent shear rate reached $10^{5} \mathrm{~s}^{-1}$. Pressure became high enough so that shear heating and pressure-dependence of the viscosity could not be neglected. Moreover, spurt and chaotic defects related to wall slip were encountered. Nevertheless, we again used classical data processing. We obtained viscosity at high shear rate which is lower than the viscosity obtained with the Carreau-Yasuda extrapolation of the moderate shear rate data. In order to discuss the origin of this difference, we developed a flow numerical simulation in the capillary where we took into account pressure and temperature dependent viscosity. We deduced that at shear rate until $10^{5} \mathrm{~s}^{-1}$, the decrease of the pressure due to the heat dissipation and its growth due to the piezodependency cancelled out mutually. In other words, the experimental results at high shear rate should still be valid.

We exploited the experimental rheological data and we tested them by comparing the results of injection moulding numerical simulation to measurements in an instrumented mould. In the simulation, we overestimated the measured pressure.

\section{ACKNOWLEDGEMENT}

The authors gratefully acknowledge financial support from the French Research National Agency ANR for Microconnect project. The injection moulding tests were carried out thanks to G. Regnier and N. Bou Malhab from LIM of Ensam Paris.

http://www.microinjectionmolding.eu/

\section{REFERENCES}

[1] Whiteside BR, Spares R, Howell K, Martyn MT, Coates PD, Micromolding: extreme process monitoring and inline product assessment, Plastic rubber and composites 34 (9), 2005

[2] Takahashi H, et al. Rheological behavior of SAN PC blends under extremely high shear rate, Journal of Applied Polymer Science, Vol 37, 1989

[3] Cardinaels R, et al., Evaluation and comparison of routes to obtain pressure coefficients from high-pressure capillary rheometry data, Rheology Acta, 2007

[4] Agassant J.-F., Avenas P., Sergent J.-P., Vergnes B., Vincent M. : La mise en forme des matières plastiques, Paris Lavoisier TEC \& DOC, 73-74, 1996.

[5] Couch M. A.; Binding, D. M.; High pressure capillary rheometry of polymeric fluids, Polymer, 2000 [6] Laun HM, "Capillary rheometry for polymer melts revisited", Rheol acta 43: 509-528, 2004 